\title{
Research on the Development Path of Sino-Afghan Cooperative Relation
}

\author{
Jiancheng Zhang \\ Institute for Western Frontier Region of China \\ Shanxi Normal University \\ Xi' an, Shanxi, China 710062
}

\begin{abstract}
Speeding up China's westward opening, Afghanistan's strategic position will be further upgraded. SinoAfghan cooperative relation has ushered in both opportunities and challenges. Only putting Sino-Afghan cooperative relation under the distribution of China peripheral diplomacy, paying attention to the particularity of Afghanistan, it has important practical value to deepen Sino-Afghan cooperative relation by integrating political cooperation, economic cooperation, security cooperation, cultural cooperation and regional affairs cooperation.
\end{abstract}

Keywords-China; Afghanistan; cooperative relation; development path

\section{INTRODUCTION}

Since ancient times, China and Afghanistan are the narrow strips of water neighbors and have a good relationship with each other. The ancient Silk Road is the historical witness of the friendly relations between the two countries. In September 2013, President Xi Jinping had proposed the strategy of Silk Road Economic Belt, which gave new opportunities in ChinaAfghan cooperation. In October 2014, China and Afghanistan had signed < The Joint Declaration on Deepening Strategic Partnership>, which gave the rich times connotation of ChinaAfghanistan cooperation under new changes of the world pattern. As the 60th anniversary of the establishment of the "year of China-Afghanistan friendly cooperation" The year of 2015 is the new start of the friendly and cooperative relations between two countries. This article plans to discuss the development path of the China-Afghanistan cooperation relationship in order to highlight the time value on further deepening China-Afghanistan strategic cooperative partnership.

Afghanistan, as one of the hubs of Chinese strategy of westward opening, the Afghanistan situation in Central Asia is extremely interconnected. Promoting the friendly development of China-Afghanistan cooperative relation is a win-win choice for complying with the development of times. Collaboration shall be promoted in a step-by-step, focused, effective and orderly manner in the field of politic, economic, security, humanity and regional affairs, etc. Deepening ChinaAfghanistan strategic partnership, then China should make great efforts to build their partnership into a good example of cooperation between China and its neighboring countries, as well as into a win-win model of connectivity among countries

Fund Project: Social Science Fund Project of Shaanxi Province "Research on Reconstruction of the Afghan nation-state in the perspective of Silk Road Economic Belt"' (Project No. 2015E010). along the Silk Road Economic Belt. This will have farreaching time significance.

\section{DEVELOPMENT PATH}

\section{A. Political Cooperation: To Build a More Mutual-trust Community of Interests and Community of Destiny between China and Afghanistan}

As the product of power game, the political decisions of a national government shall be influenced by many uncertain factors, especially in Afghanistan. Afghan nationalities are numerous and fragmenting, thus it is hard for them to be unified because if it does, there will be a threat posed to another's social existence by any expansion of one side's interests. However, they cannot separate because their social existence is interdependent with each other. One of the consequences that the game of Afghanistan tribes for interests has been continuing, are to lead to the central government's relatively weak power. The reality of this weakness reminds us that China should practice the foreign concept of amity, sincerity, mutual benefit and inclusiveness and also take the great nation responsibility for building the surrounding community of destiny positively under the precondition that not interfering in the internal affairs of Afghanistan.

Firstly, China and Afghanistan need to have enough political courage to control their respective nationalist sentiment. The two countries should adhere to the principle of common development and construct cooperative management mechanism in order to combine into a close community of interests. They also need to strengthen all domestic policy coordination of departments and regions with each other in the governmental diplomatic level and rationalize the Tiao-kuai relation to form a positive and orderly foreign coordination mechanism; they cooperate fully with each other, promote the implementation together to strive to remove the government system limit of China-Afghanistan political cooperation. Secondly, China should raise the sense of community of interests to a closer one between China and Afghanistan step by step and then to the regional identity consciousness of two countries gradually. "China shall provide another dynamic mechanism to build, maintain and correct the political, economic, security and other relevant order of the Central Asian region as well as to achieve sustainable peaceful and harmonious development and common prosperity in the 
region."; and provide the mutual-trust social psychological identity for building Silk Road Economic Belt together.

\section{B. Economic Cooperation: To Build a More Mutually Beneficial Economic Cooperation Mechanism between China and Afghanistan}

The fundamental power of continuously deepening the China-Afghanistan economic cooperation depends on the continuous synergy, pursuit and satisfaction for common interests by two countries. Mr. Vahe Dula wahi, directorgeneral of ministry of economic cooperation of Foreign Affairs of Afghanistan, believes that "This whole area would be completely realized in the revival of the Silk Road by turning Afghanistan into a pivot of regional trade and transport, as well as by connecting the increasingly active east-west and northsouth corridors of the Silk Road." But Afghan continuous turbulent political scene has caused "Stressing the trade, ignoring the investment" of the China-Afghanistan economic cooperation. This pattern obviously deviates from the idea of long-term sustainable development, China-Afghanistan economic cooperative mechanism needs to improve and perfect with the times.

Firstly, mechanism for economic and trade cooperation should be go ahead of the rest. In China-Afghanistan economic cooperation, economy and trade guide first. The two governments agree to "make China-Afghanistan economic cooperation and trade cooperation mechanism function fully, hold the second meeting of the Joint Committee of Economics and Trade to discuss the expansion and deepening of trade and investment cooperation of two countries."Secondly, source and cooperation mechanism should follow up. Strengthening allround pragmatic cooperation of the energy field is the key layout to deepen China-Afghanistan economic cooperation. The two countries should adhere to the win-win cooperation concept of equality and mutual trust, tolerance and mutual learning, strongly support the cooperation between Chinese enterprises and the relevant departments of Afghanistan in traditional energy field; and they also should promote cooperation in the field of bilateral renewable energy actively and lead the China-Afghanistan energy cooperation to a new level. Thirdly, it is about the foreign investment guide mechanism for navigation. China should strengthen the consciousness of the top-level design and establish a national strategic level of foreign investment guidance mechanism. According to the Afghan requirements, the Chinese government should encourage and regulate the behavior that Chinese enterprises "go outside" to invest in Afghanistan. China and Afghanistan should be promoted to build the free trade zone (park) together in a proper time and to make the service trade liberalization so as to form a large-scale, clustering and local foreign investment pattern. Fourthly, it is about the foreign investment risk control system. Both opportunities and risks exist in the China-Afghanistan economic cooperation. Chinese government must establish and perfect the foreign investment risk control system; and it also takes full consideration in Afghan internal risk spillover and does a good job in risk assessment and control to make the foreign investment income maximum.

\section{Safety Cooperation: To Build a More Interdependent Security Coordination Mechanism between China and Afghanistan}

Those who suit their actions to the times are wise. China and Afghanistan have widely differences in political system, economic level, social system, cultural tradition and so on, but based on the safety claims of the core national interests two countries still have one thing in common. They are all devoted to promoting economic development and maintaining social stability and achieving peace and prosperity. In the absence of a more interdependent security collaboration mechanism, it is so difficult for China-Afghanistan cooperation to achieve the maximum efficiency expected when facing the various traditional and non-traditional security threats factors that emerge endlessly. President Xi Jinping "advocates a sustainable Asia security concept of common, integration and cooperation, and then innovates safety concept to build a new framework of regional security and cooperation and makes efforts to find out a co-construction, sharing and win-win way to develop safely for Asia." There is no doubt that it provides action guidance for China and Afghanistan to carry out the safety cooperation.

Firstly, the concept should be changed and the sense of beforehand prevention should be intensified. In the 2014 edition of Country Risk Analysis Report published by Sinosure, Afghanistan was defined into the country where country risk level increased and rating was declined. As for developing the China-Afghanistan cooperative relationship, it is very important to strengthen the beforehand-prevention awareness of safety cooperation in advance. Secondly, it is to establish the risk pre-judgment and the formation of mechanism for security preparedness. Chinese government needs to make sufficient risk pre-judgment and formulate feasible security preparedness, in adhering to the principle of "Giving before taking, giving more than taking", and does not interfere in internal affairs of Afghanistan and not entangle the interest dispute of Afghan tribes to reduce the untoward reactions caused by the problem of Chinese itself. China should carry out preventive diplomacy actively and handle with the different views between two countries properly. Thirdly, it is the law enforcement and construction of the united executing mechanism. China should strengthen the pragmatic cooperation to struggle to create a well China-Afghanistan cooperative environment in drug control and counter-terrorism, border management, and other key security law enforcement fields. For example, in drug control field, China should enhance the bilateral contract in the field of agricultural development and alternative planting; in the field of combating terrorism, China should continue to strengthen the bilateral cooperation against terrorism of two countries and strengthen the training to Afghanistan in defense and policing law enforcer. The fourth is the international cooperation and the construction of contain mechanism. Chinese government, when facing the serious situation of the non-traditional security factors which has a strong international mobility such as Terrorism, economic security, drug trafficking, transnational crime, etc., should further strengthen the bilateral collaboration in non-traditional security field of two countries and resolve the risks of non-traditional security issues brought to China- 
Afghanistan cooperation. Meanwhile, China should cooperate with neighboring countries actively to find out and build jointly a long-term safety mechanism that contributes to the construction of community of destiny.

\section{Cultural Cooperation: To Build a more Mutual Cultural Exchange Mechanism between China and Afghanistan}

The cultural exchanges between the two people are glorious and shining under the sun. Two countries use the history of the ancient Silk Road as a proper opportunity to fully evaluate the new situation and development of two countries' relations under the new era, and to develop by the fundamental mode of thinking the big events while taking on the little responsibilities. In that way, two countries are capable of achievement of the bilateral cultural exchanges and cooperation pattern. By giving the same proportion of attention to the government and public diplomacy, they make efforts to establish a mutual learning and sharing cultural exchange mechanism.

Firstly, the government diplomacy should be as the leading and enhance the level of official cultural exchange. Chinese government should strengthen exchanges and cooperation with Afghan government in culture, education and other fields; and strengthen cultural affinity to Afghan culture and promote the mutual trust relationship between China and Afghanistan. On the one hand, through the form of establishing Confucius Institute, Confucius Classroom etc. for local people, they would have superior teaching resources and learning environment to study Chinese; On the other hand, China should take the layout of "the diplomacy of studying aboard" and various measure to encourage and support Afghan students who study abroad to China for learning. "No matter from China's reality or the international experience, staying in China for education, driven by the political and economic interests, is a good point cut for China to promote its soft power". Secondly, the public diplomacy should be the main body and improve the quality of public cultural exchanges. China should attach importance to the public diplomacy and strengthen non-governmental exchanges and expand the field of cultural cooperation. It also should actively construct the linkage mechanism of non-governmental cooperation such as think tank, news media, academic institution and social groups, etc., and then form a more comprehensive, more detailed, more flexible exchange mechanism of folk culture. Thirdly, there shall be a collaborative interaction between government and public diplomacy; China shall improve the mechanism of cultural and educational exchanges. Good communication between government diplomacy and public diplomacy shall be achieved in seamless connection, and cooperate to build the overall communication and cooperation mechanism. Chinese government shall realize the harmonious dialogue, mutual learning and common prosperity of the native and heterogeneous civilization; and then promote the construction of the tighter China-Afghanistan community of destiny.

\section{E. Regional Cooperation: To Build a More Mutual- Intelligibility Regional Collaboration Mechanism between China and Afghanistan}

The criteria for classification of regional cooperation are not the same. According to the space size of cooperation field, regional cooperation can be divided into diverse cooperation situation, such as sub-regional cooperation in the region, national large regional cooperation, global cooperation etc. Ghani, president of Afghanistan, says that "As China adheres to being on good terms with its neighbor Afghanistan and giving benefits to Afghanistan, so it becomes possible to make Afghanistan cooperate with China as well as diversify their regional cooperation ." China-Afghanistan regional cooperation shall insist on the "for people, practical, effective and innovative" principle to build a regional collaboration mechanism with good accessibility.

Firstly, with the assistance of SCO, Chinese government should enhance China-Afghanistan regional cooperation and optimize the allocation of regional resources. Two countries respectively are the members and observers of SCO, and both of them also have a good dialogue platform. The in-depth advance of China-Afghanistan cooperative relationship shall be further positioned on the basis of the relationship between Afghanistan and SCO; and it will make China improve the capability of participating the Afghan national rebuilding under the multilateral situation. Secondly, based on the Silk Road Economic Belt, Chinese government shall deepen ChinaAfghanistan regional cooperation and gather the power of regional organization. The construction of the Silk Road Economic Belt is the important and practical field for China's strategy of westward opening, aiming at jointly building a multilateral cooperation and win-win platform which is also fair, reasonable, open, effective and safe. Its effectiveness of the construction is closely related to the participation of countries along. It is important to focus on regional multilateral cooperation and to make the demonstration and guidance of China-Afghanistan bilateral cooperation work fully; China also should encourage the countries along to participate in building "the Silk Road Economic Belt" and then come into being the "safety net" which could help China strategically break through the containment regional organizations such as TPP, TTIP etc. Thirdly, taking the United Nations as the ligament, China should expand ChinaAfghanistan regional cooperation and integrate the multiple coordination mechanism of the regional organization. Within the framework of UN, China shall promote the channels for dialogue on Afghan issues such as China - Afghanistan Pakistan trilateral dialogue, 6+1 dialogue on Afghan issue and dialogue on Istanbul process, etc.; China also should integrate effectively regional dialogue and cooperation mechanism such as SCO、CAREC、SAARC、ECO、OIC and CICA, etc. and assist Afghanistan in the process of peaceful rebuilding.

\section{CONCLUSION}

Under the background of the in-depth advance of China's strategy of westward opening, Afghanistan is becoming one of the pivot countries in the important strategy of China's national interests day by day. Adhering to the co-consulting, coconstruction, sharing and win-win principle, building the 
community of interests and the community of destiny between China and Afghanistan and promoting the development of China-Afghanistan cooperation are the win-win choice of benefiting both the safety of China's western region and the national building of Afghan nation. While the security issue is the "Achilles' Heel" of China-Afghanistan cooperation, China's self-role definition should be cautious in thinking, lowkey in acting and courageous in undertaking. China should support to explore, plan and practice the "Afghan governed by itself" strategy of "Afghan leading" and "Afghan possessing", and promote the further sustainable development of ChinaAfghanistan strategic partnership.

\section{REFERENCES}

[1] Norbert, Elias. The Process of Civilization: The Research in Social and Psychological Origin of Civilization. Shanghai Translation Publishing House, 2013: 39.

[2] Yang Cheng. Build China-Central Asia "Community of Destiny and Interest" [N]. Oriental Morning News, 2013-09-12(A18).

[3] The Afghan Scholar's Calling on Integrating the Five Global Silk Road Projects. [EB/OL]. http://finance.people.com.cn/n/2014/0628/c100425212643.html.

[4] The Joint Declaration on Deepening the Strategic Partnership between
China
and Afghanistan.
[EB/OL]. http://news.xinhuanet.com/world/2014-10/28/c_1113016324.htm.

[5] Xi Jinping: China shall advocate actively the common, comprehensive, cooperative, and sustainable Asia security concept. [EB/OL]. http://news.xinhuanet.com/world/2014-05/21/c_1110792359.htm.

[6] Jing Hua. The 2014 edition of <Country Risk Analysis Report> published by SINOSUER [J]. International Finance,2014, (9) : 54.

[7] Lei Mo. China's Layout of "The Diplomacy of Studying Aboard" [J].South Reviews, 201（10）: 51.

[8] Interviewing the Afghan President Ashraf. Ghani. Ahmed Karzai [EB/OL].

http://news.xinhuanet.com/world/2014-10/28/c_1113014223.htm. 